\title{
Pontocerebellar hypoplasia type 3
}

\author{
INSERM
}

\section{Source}

INSERM. (1999). Orphanet: an online rare disease and orphan drug data base.

Pontocerebellar hypoplasia type 3. ORPHA:97249

Pontocerebellar hypoplasia type 3 (PCH3), also known as cerebellar atrophy with progressive microcephaly (CLAM) is a rare form of pontocerebellar hypoplasia (see this term) with autosomal recessive transmission characterized neonatally by hypotonia and impaired swallowing and from infancy onward by seizures, optic atrophy and short stature, but none of the clinical findings are specific for $\mathrm{PCH}$. 